\title{
A Comparison of Analytical Methods for the Numerical Taxonomy of Yeasts
}

\author{
By G. R. JONES* \\ Department of Microbiology, University of Glasgow, Anderson College, \\ Glasgow GI I $6 N U$
}

(Received 20 January 1975)

\section{SUMMARY}

Four methods of numerical analysis were tested to assess the taxonomic relationships of species of yeasts in 20 genera using characters obtained from standard descriptions. Relationships varied according to the analytical method employed. It is suggested that a reduction in the present number of genera may be necessary to justify the taxonomic rank of genus.

\section{INTRODUCTION}

The classification of yeasts is a subject of some controversy (Barnett, I966; van der Walt, $1970 \mathrm{a}$ ), but numerical analyses have facilitated the investigation of the taxonomy of various yeasts (Kocková-Kratochvílová et al. 1970; Campbell, 1973).

Present systems of classification characterize genera by morphological and reproductive properties and species by physiological properties (The Yeasts, a Taxonomic Study, 1970), such that differentiation between genera may depend upon a few properties. Numerical analysis provides a classification scheme based on overall similarity. However, selection or weighting of properties has occurred before analysis (Campbell, 1973) in accordance with certain properties of the species under consideration. The present investigation was intended to determine the relationships of 26 yeast species of 20 genera by different methods of numerical analysis of standard descriptions in The Yeasts, a Taxonomic Study (1970), using all properties which were applicable to all the yeasts.

\section{METHODS}

Yeasts. The species studied are listed in Table I and were selected as part of a study of cell-wall antigens (Jones \& Stewart-Tull, 1975). Three additional species of both Candida and Saccharomyces were included to assess the homogeneity of these genera.

Characters. All the characters of the 26 species as described in The Yeasts, a Taxonomic Study (1970) were included if, but only if, they were listed for all the species, e.g. as the splitting of arbutin was not listed for some species this character was excluded from the list (cf. Barnett \& Pankhurst, 1974). A character described as rarely positive was regarded as negative, and vice versa. Cell dimensions were taken as the average of the listed limits of length and width. Osmotic tolerance was regarded as growth in the presence of $12 \%(\mathrm{w} / \mathrm{v})$ sodium chloride or $50 \%(\mathrm{w} / \mathrm{w})$ glucose.

\footnotetext{
* Present address: Department of Medical Mycology, University of Glasgow, Anderson College, Glasgow
} GII 6NU. 


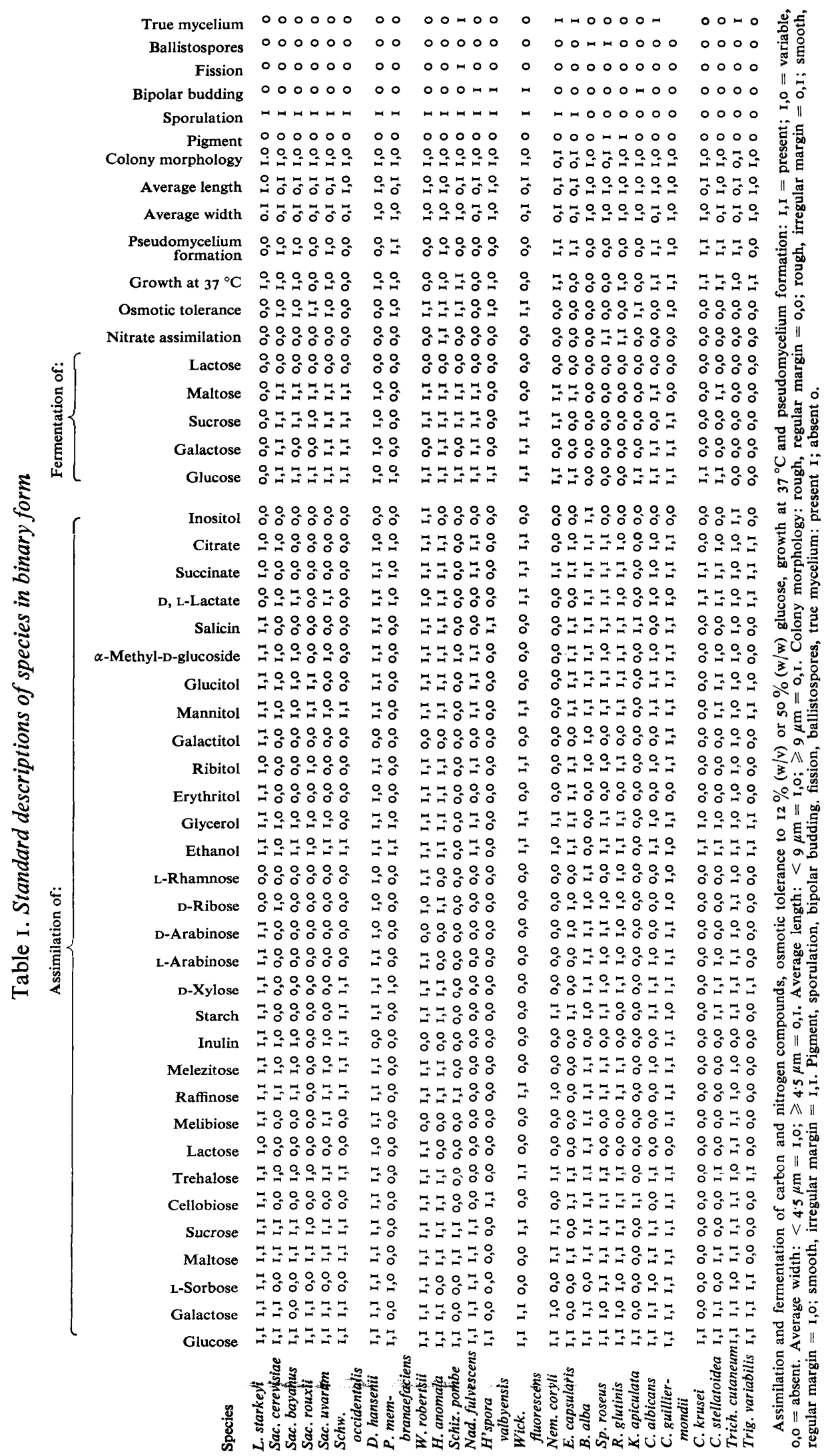


Coding of characters. Characters were coded in binary form (Table I). To take into account variable characters, the assimilation, fermentation and any other variable properties were coded 0,0 for negative, I, o for variable, and I,I for positive.

Numerical analyses. Similarity between species was assessed by the simple matching coefficient, $S_{\text {SM }}$ (Sokal \& Michener, 1958), which includes positive and negative matches:

$$
S_{\mathrm{SM}}=\frac{a+b}{a+b+c},
$$

where $a$ is the number of positive matches, $b$ the number of negative matches and $c$ the number of mismatches of corresponding characters of two species.

Taxonomic distance was expressed as the average squared distance, $d^{2}$ (Sokal, 196I):

$$
d^{2}=\frac{\Sigma\left(x_{\mathrm{A}}-x_{\mathrm{B}}\right)^{2}}{n},
$$

where $n$ is the total number of characters, $x_{\mathrm{A}}$ is the binary score for character $x$ of species A and $x_{\mathrm{B}}$ is the score for the corresponding character $x$ of species $\mathrm{B}$.

The clustering methods of single linkage (Sneath, 1957), complete linkage (Sørensen, 1948), average linkage (Sokal \& Michener, 1958) and 'error sum of squares' (Ward, 1963) were tested. Numerical analyses were carried out using the CLUSTAN IA set of programs (Wishart, 1969) amended by Middleton (1972) in an IBM 370/ 158 computer at the Edinburgh Regional Computing Centre.

\section{RESULTS}

In the dendrogram formed by the single linkage method (Fig. I) all the species were clustered about the $70 \%$ similarity level (distance level 0.3 ). A noticeable feature was the individuality of Trichosporon cutaneum which was only remotely related to the other yeasts.

In the complete linkage dendrogram (Fig. 2) all the yeasts were related at the $36 \%$ similarity level (distance level $0 \cdot 64$ ). In contrast to single linkage, Trich. cutaneum was related to Lipomyces starkeyi and Bullera alba. Other differences in cluster composition were also apparent, e.g. Sporobolomyces roseus and Rhodotorula glutinis were included in the cluster containing Debaromyces hansenii, Wingea robertsii, Hansenula anomala and Candida guilliermondii in the single linkage dendrogram, whereas with complete linkage they were associated with L. starkeyi, B. alba and Trich. cutaneum.

In the average linkage dendrogram (Fig. 3) all the yeasts were related near the $50 \%$ similarity level (distance level 0.5 ). Comparison with the dendrograms formed by single and complete linkage methods revealed that average linkage corresponded more closely to complete linkage than to single linkage.

The dendrogram formed by the error sum of squares method (Fig. 4) showed the species to be related at the $2 \cdot 3$ distance level (percentage similarity values are not applicable to this method). This dendrogram was most similar to the one formed by complete linkage (Fig. 2). Two major clusters were apparent, but these had no obvious distinguishing features, e.g. division into asco- and anascosporogenous yeasts. An arbitrary selection of the 0.5 distance level divided the species into five clusters:

\section{Cluster I. L. starkeyi, B. alba, Trich. cutaneum, Sp. roseus and R. glutinis}

The species most closely related were $S p$, roseus and $R$. glutinis, followed by $L$. starkeyi and $B$. alba. Trichosporon cutaneum was associated with the latter two species, but not closely. 
Percentage similarity

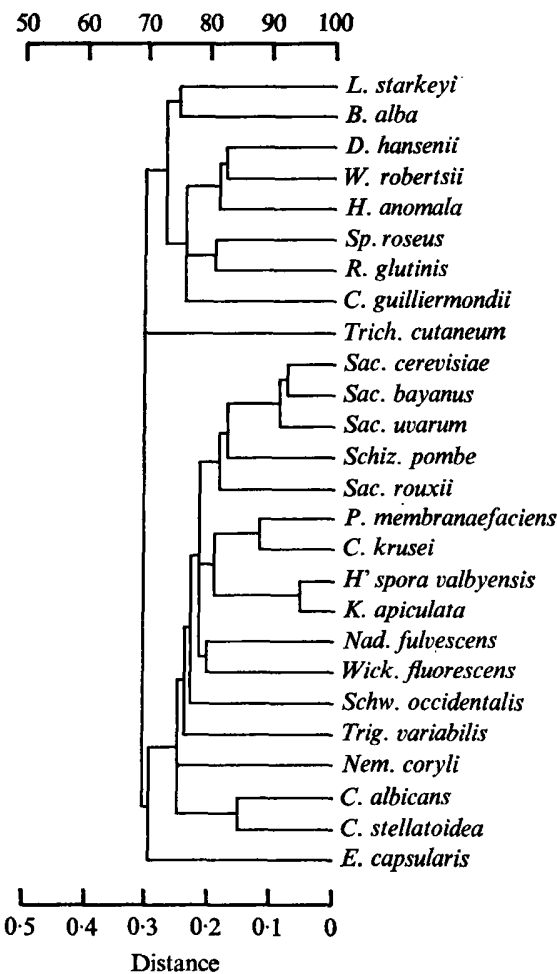

Fig. I

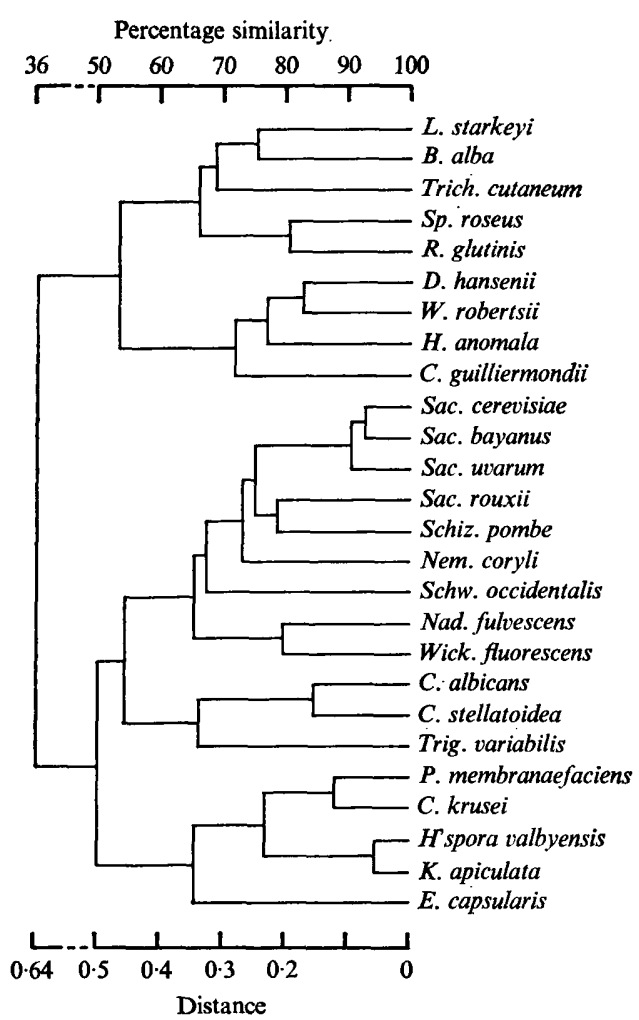

Fig. 2

Fig. I. Taxonomic dendrogram formed by single linkage analysis of standard descriptions of species.

Fig. 2. Taxonomic dendrogram formed by complete linkage analysis of standard descriptions of species.

\section{Cluster 2. D. hansenii, W. robertsii, $H$. anomala and C. guilliermondii}

As the ascosporogenous counterpart of $C$. guilliermondii is Pichia guilliermondii, the association of the former with the other species in this cluster agreed with similar relationships observed by Campbell (1973).

Cluster 3. Saccharomyces cerevisiae, Saccharomyces bayanus, Saccharomyces uvarum, Schwanniomyces occidentalis, Saccharomyces rouxii, Schizosaccharomyces pombe, Nematospora coryli, Nadsonia fulvescens and Wickerhamia fuorescens

Saccharomyces cerevisiae, Sac. bayanus and Sac. uvarum appeared sufficiently closely related to be considered as one species. Schwanniomyces occidentalis was more closely associated with these Saccharomyces species than was Sac. rouxii which formed a cluster with Schiz. pombe and Nem. coryli. A distinct minor cluster consisting of the bipolar budding yeasts Nad. fulvescens and Wick. fluorescens completed the larger cluster.

\section{Cluster 4. Endomycopsis capsularis, Candida albicans and Candida stellatoidea}

Candida albicans was associated with $C$. stellatoidea, both of which van der Walt (1970 b) regarded as Syringospora species. Endomycopsis capsularis, although forming a cluster with the Candida species, was related distantly to them. 


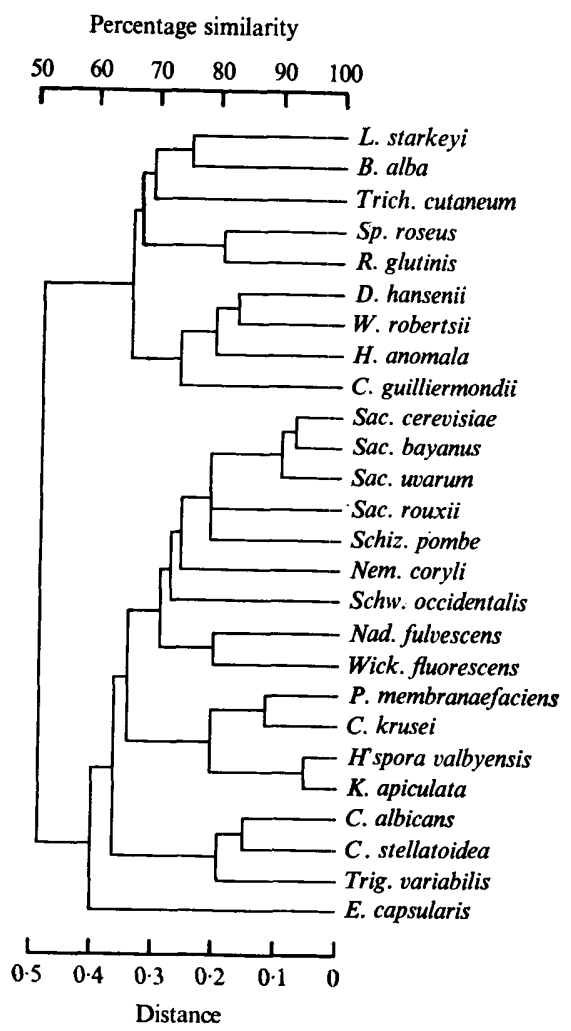

Fig. 3

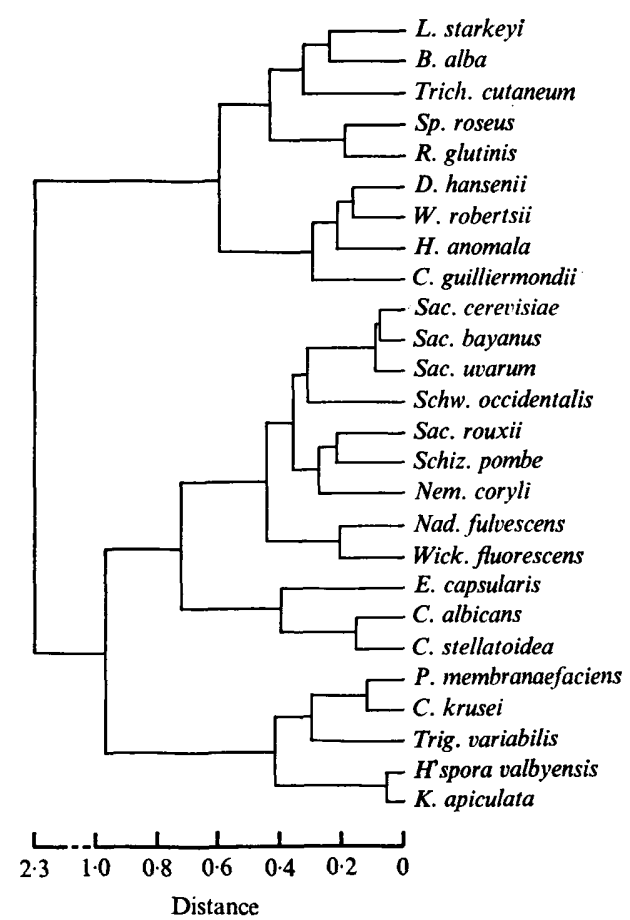

Fig. 4

Fig. 3. Taxonomic dendrogram formed by average linkage of standard descriptions of species. Fig. 4. Taxonomic dendrogram formed by error sum of squares analysis of standard descriptions of species.

Cluster 5. Pichia membranaefaciens, Candida krusei, Trigonopsis variabilis, Hanseniaspora valbyensis and Kloeckera apiculata

As the ascosporogenous form of $C$. krusei is Pichia kudriavzevii, its relationship with $P$. membranaefaciens was expected, although a closer association with the species of cluster 2 would also be expected. Trigonopsis variabilis was not closely related to $C$. krusei and $P$. membranaefaciens, with which it formed a cluster. The apiculate yeast $H$ 'spora valbyensis and its anascosporogenous counterpart $K$. apiculata were related only distantly to the other species of Cluster 5 .

\section{DISCUSSION}

Cluster composition and linkage levels are dependent on the criteria which permit the entry of a species to a cluster. The differences apparent in the dendrograms arising from the various linkage methods indicate that caution should be observed in the interpretation of relationships determined by a single method of numerical analysis. Although the error sum of squares method has not been used in biological systems until now, of the methods tested it appeared to produce the most distinct differentiation into well-separated groups. It is also possibly one of the most suitable hierarchial fusion methods. 
Although the majority of the species in this investigation were type species, they were not necessarily representative of the respective genera. Nevertheless, if a species is assigned to a particular genus it must possess properties which are typical of that genus. Comparison of individual species from a variety of genera should indicate the relative taxonomic positions of these genera. Present systems of classification are constructed chiefly for identification purposes and consequently are lists of yeasts and their properties with little regard to relationships (Barnett \& Pankhurst, 1974).

The dendrograms illustrate the heterogeneity of the 26 yeasts and also the considerable sharing of properties. Species that clustered at similarity levels of $70 \%$ or greater were considered as members of the same genus (Campbell, 1972). In the single linkage, complete linkage and average linkage dendrograms (Figs. I, 2, 3) there were 3, I I and 8 'genera' respectively at this level. In the 'error sum of squares' dendrogram (Fig. 4) a distance value of 0.3 was approximately equivalent to $70 \%$ similarity and at this level 13 'genera' were apparent. These results emphasize the difficulties that arise from the numerical taxonomic analysis of a biological system using only one clustering technique. It appears there might be insufficient differences between some of the existing genera to warrant their separation. Campbell (1971, 1972, 1973) recommended amalgamation of certain genera on the basis of numerical analyses. The present work indicates that if the rank of genus is to be used meaningfully, there should be fewer genera.

I thank Professor A. C. Wardlaw for his helpful suggestions and discussion, and Dr D. E. S. Stewart-Tull for his encouragement and advice.

\section{REFERENCES}

BARNETt, J. A. (1966). A biochemical interpretation of some taxonomic differences between yeasts. Nature, London 210, 565-568.

Barnett, J. A. \& Pankhurst, R. J. (1974). A New Key to the Yeasts. Amsterdam and London: North Holland Publishing Co.

CAmpbell, I. (1971). Numerical taxonomy of various genera of yeasts. Journal of General Microbiology 67, 223-231.

CAMPBELL, I. (1972). Numerical analysis of the genera Saccharomyces and Kluyveromyces. Journal of General Microbiology 73, 279-301.

CAMPBelL, I. (1973). Numerical analysis of Hansenula, Pichia and related yeast genera. Journal of General Microbiology 77, 427-44I.

Jones, G. R. \& Stewart-Tull, D. E. S. (1975). Antigenic analyses of yeast cell-walls. Sabouraudia r3, 94-109.

Kocková-Kratochvílová, A., Sedlárová, L., Vojtková-Lepšíková, A. \& Šandula, J. (I970). Taxometric Study of the Genus Saccharomyces (Meyen) Rees. Saccharomyces cerevisiae Hansen and related species. Part II. Bratislava: Slovak Academy of Sciences.

MidDleton, R. L. (1972). ERCC amendments to CLUSTAN iA. Edinburgh: Edinburgh Regional Computing Centre Program Library Unit.

SNEATH, P. H. A. (1957). The application of computers to taxonomy. Journal of General Microbiology 17, $201-226$.

SoKal, R. R. (196I). Distance as a measure of taxonomic similarity. Systematic Zoology ro, 70-79.

SoKAL, R. R. \& Michener, C. D. (1958). A statistical method for evaluating systematic relationships. University of Kansas Science Bulletin 38, 1409-1438.

Sørensen, T. (1948). A method of establishing groups of equal amplitude in plant sociolog y based on similarity of species content and its application to analyses of the vegetation on Danish commons Biologiske Skrifter 5, I-34.

The Yfasts, a Taxonomic Study (1970), 2nd edn. Edited by J. Lodder. Amsterdam \& London: North Holland. 
VAN DER WALT, J. P. (1970a). Criteria and methods used in classification. In The Yeasts, a Taxonomic Study (1970), 2nd edn., pp. 34-I I 3. Edited by J. Lodder. Amsterdam and London: North Holland Publishing Co. VAN DER WALT, J. P. (1970b). The genus Syringospora Quinquad emend. Mycopathologia et mycologia applicata 46, 23I-243.

WARD, J. H. (I963). Hierarchial grouping to optimize an objective function. Journal of the American Statistical Association 58, 236-244.

WisharT, D. (1969). CLUSTAN I A. Edinburgh: Edinburgh Regional Computing Centre Program Library Unit. 